\title{
Field Distribution of Wheat Stripe Rust Latent Infection Using Real-Time PCR
}

\author{
Jiahui Yan, Yong Luo, Tingting Chen, Chong Huang, and Zhanhong Ma, Department of Plant Pathology, China Agricultural \\ University, Beijing 100193, P. R. China
}

\begin{abstract}
Yan, J.-H., Luo, Y., Chen, T.-T., Huang, C., and Ma, Z.-H. 2012. Field distribution of wheat stripe rust latent infection using real-time PCR. Plant Dis. 96:544-551.

Stripe rust of wheat, caused by Puccinia striiformis f. tritici, is of worldwide significance. Quantification of latent infection level is critical to estimate the potential for disease epidemics. In this study, field distribution of latent infection and the corresponding observed disease were studied in two growing seasons from 2009 to 2011 in Gangu, Gansu Province and Shangzhuang, Beijing, China. A previously developed real-time polymerase chain reaction (PCR) assay was applied to obtain the molecular disease index (MDX) to quantify the level of latent infection. At 1 to 3 weeks after leaf sampling, the observed disease indices (DX) were assessed in the corresponding experimental

sites. The computer software SURFER showed that the spatial distribution patterns of MDX had a linear relationship with DX in field plots with $P=0.01$. The aggregation levels of MDX correlated with those of DX in the fields. The disease foci which were correctly detected for latent infections with the real-time PCR for the Gangu and Shangzhuang field plots were 71.4 and $85.7 \%$, respectively. The triadimefon fungicide treatment focused on the detected latent infection foci reduced both the initial inoculum and disease development, resulting in an average reduction in disease area in the field plots of 73 to $81 \%$.
\end{abstract}

The fungal pathogen Puccinia striiformis f. tritici Erikss. causes stripe rust of wheat, a devastating disease with worldwide distribution $(5,6,13,21,25)$. Disease management relies on host resistance and fungicide applications. Prediction of disease development trends during the growing season would provide important information for decision making on disease management. Disease prediction relies on the accurate estimation of initial inoculum or disease level early in a season to predict epidemics (27).

In autumn or early spring, infections of $P$. striiformis f. tritici in leaves usually exist in a latent phase and such infections usually serve as an inoculum source to initiate epidemics during the season $(5,24,27)$. The latent period can be several days to weeks or as long as several months in the winter, depending on weather conditions at different geographic locations (28). Obviously, estimation of the latent infection level is important to estimate inoculum potential and assist in timely decision making on disease management. Control of the latent infection foci before symptom appearance may significantly reduce inoculum potential and cost of fungicides. Because $P$. striiformis f. tritici is an obligate fungal pathogen, incubation of leaves with latent infections is needed to promote symptom appearance. A reasonable number of plants and at least 7 to 10 days of incubation under restricted conditions are needed to estimate latent infection level. Thus, this traditional method is time consuming and labor intensive. Pan et al. (14) established a realtime polymerase chain reaction (PCR) assay to quantify the latent infection level of $P$. striiformis f. tritici in leaves but its potential field application needs to be confirmed with field experiments.

In this study, we conducted multi-season field experiments in two geographic locations in China: Gangu county of Gansu Prov-

Corresponding authors: Y. Luo, E-mail: yluo@uckac.edu,

and Z. Ma, E-mail: mazh@cau.edu.cn

Current address of J.-H. Yan: Qinghai Academy of Agricultural \& Forestry Sciences, Xining, Qinghai, 810016, P. R. China.

Current address of Y. Luo: University of California, Kearney Agricultural Center, Parlier 93648.

Accepted for publication 1 November 2011.

http://dx.doi.org/10.1094/PDIS-08-11-0680

(C) 2012 The American Phytopathological Society ince and Shangzhuang experimental center of China Agriculture University, Beijing. In the mountainous region of Gangu, P. striiformis f. tritici oversummers in volunteer wheat (28). These populations infect the winter wheat planted in early autumn at lower elevations. At these lower elevations, $P$. striiformis f. tritici overwinters in infected leaves that may serve as primary inoculum the following spring. As these populations expand, their inoculum is dispersed eastward into neighboring wheat-producing regions. Thus, the latent infection level in the fields in both autumn and early spring in this region is important for estimating the inoculum potential which may influence the regional disease epidemics in China through long-distance disease spread (28). On the other hand, Beijing belongs to another epidemic zone where winter is cold and summer is hot. Here, $P$. striiformis f. tritici is unlikely to survive between seasons (28). The epidemics on seedlings in autumn are unusual and those in the spring season rely on the exogenous inoculum coming from southern regions. These latent spring infections can serve as a source of initial inoculum for epidemics later in the season.

The objectives of this study were to (i) determine the field spatial distributions of latent infection of wheat stripe rust and the predictability of using the established real-time PCR assay to determine the spatial distribution patterns of the disease index in the field plot, and (ii) estimate the efficacy of fungicide control by focusing on the determined latent infection foci in the fields to reduce disease development.

\section{Materials and Methods}

Gangu field plots. In Gangu, four experimental field plots were identified in each of 2 years. In the 2009-10 growing season, two field plots, GF1-1 and GF1-2, were selected in Wang Village $\left(105.33^{\circ} \mathrm{E}\right.$ and $\left.34.68^{\circ} \mathrm{N}\right)$ at an elevation of $1,690 \mathrm{~m}$. Two other fields (GF1-3 and GF1-4) were selected in Dong Village $\left(105.35^{\circ} \mathrm{E}\right.$ and $34.15^{\circ} \mathrm{N}$ ) at an elevation of $1,770 \mathrm{~m}$. The distance between these two locations is $59 \mathrm{~km}$. In the 2010-11 growing season, two field plots (GF2-1 and GF2-2) were selected at Wang Village and designated as GF1-3 and GF1-4, respectively. Two other field plots, GF2-3 and GF2-4, were selected at Dong Village. Each field was divided into 36 subplots (Table 1). Table 1 provides additional information on the experimental design. The fields were rain fed and the soil fertility was low. A moderately resistant wheat ('Lintiao157') was planted in this field.

Natural infections of stripe rust occurred in this area. In the 2009-10 season, leaf sampling was conducted at wheat growth 
stage GS22 (26; Table 1) when no wheat stripe rust symptoms were visible. In each subplot, 30 leaves were randomly collected as a replicate and processed in bulk to extract DNA, the real-time PCR was run (14), and molecular disease index (MDX) was obtained as described below. The disease incidence (DI; number of diseased leaves/total number of leaves assessed) and disease severity (DS; visually assessed average leaf area with symptoms/average total leaf area) of the corresponding subplots were assessed 9 days after leaf sampling, when wheat stripe rust symptoms appeared. The disease index (DX; 28) was then calculated as DX $=\mathrm{DI} \times \mathrm{DS}$ $\times 100$. Thus, for each subplot, we obtained latent infection level as $P$. striiformis f. tritici DNA quantity and corresponding DX data.

The experiments were continued in autumn of the 2010-11 growing season (Table 1). The MDX was obtained for each subplot (see data analysis below) and used to draw the maps of field distribution of latent infection of wheat stripe rust (see data analysis below) for the field plots GF2-1 and GF2-3. The fungicide treatment, triadimefon 250WP (Meibang, China) was then applied to the selected latent infection foci in these two field trials on 27 October 2010. In each detected latent infection focus, triadimefon 250WP at $374.8 \mathrm{~g} \mathrm{ha}^{-1}$ was applied with water in a final volume of 1,000 liters $\mathrm{ha}^{-1}$ with a back sprayer in each subplot. No-fungicide controls were arranged in the field trials GF2-2 and GF2-4. The DI and DS in the subplots of each field were then assessed after the appearance of wheat stripe rust symptoms in the control plots. Disease assessment was conducted two more times on the dates listed in Table 1.

Shangzhuang field plots. At Shangzhuang $\left(116.46^{\circ} \mathrm{E}\right.$ and $39.92^{\circ} \mathrm{N}$, at an elevation of $56 \mathrm{~m}$ above sea level), three field plots (SF1-1, SF1-2, and SF1-3) were selected during the 2009-10 season and four field plots (SF2-1, SF2-2, SF2-3, and SF2-4) were selected during the 2010-11 season. Similarly, each field was divided into a different number of subplots (Table 2). Additional information on the experimental design is provided in Tables 2. Flood irrigation was used in these field plots. A moderately resistant wheat, 'Jing0045', was planted in this field.

Due to the dry weather in spring in this region, disease promotion was performed by planting the susceptible wheat 'Mingxian 169' in the center of each field (100 seeds) and inoculation was conducted on 16 April 2010 by spraying $30 \mathrm{ml}$ of spore suspension $\left(5 \times 10^{4}\right.$ spores $\left./ \mathrm{ml}\right)$ on leaves of these susceptible plants. The inoculated plants were covered with plastic sheets overnight to maintain high humidity. These inoculated plants started to show stripe rust symptoms on 28 April 2010 and were removed from the fields on 2 May 2010. The leaf sampling was conducted on 5 May 2010 at growth stage GS22 (26; Table 2), and 30 leaves were randomly collected as a replicate.

The experiments were continued in spring of the 2011 season (Table 2). Inoculation, leaf sampling, and processing were conducted as described for the 2010 season. Similarly as in Gangu, the fungicide treatment was applied in the selected latent infection foci in field plots SF2-1 and SF2-3 on 10 May 2011, and the nontreated controls were field plots SF2-2 and SF2-4. Disease assessment was continued on dates shown in Table 2.

DNA extraction from plant leaf tissues. To extract DNA from sampled wheat leaves, $1-\mathrm{cm}$-long sections were removed. The cetyltrimethylammonium bromide method following the previously published protocols (2), with minor modification $(14,30)$, was applied to obtain DNA for PCR. The extracted DNA was dissolved in $100 \mu \mathrm{l}$ of distilled water and diluted $60 \times$ and $500 \times$ for real-time PCR amplification of $P$. striiformis f. tritici DNA and wheat DNA, respectively.

Real-time PCR assay. The following primer pair specific to $P$. striiformis was used: Pst-F (5'-TAAGGTGTCTGATACCGT TGTCG-3')/Pst-R (5'-GCTAGTTTACGGAGATCAGAGT-3'). The following wheat-specific primer pair was also used: TAG2315F

Table 1. Summary of experimental design in Gangu, China, field plots during the 2009-10 and 2010-11 growing seasons ${ }^{\mathrm{a}}$

\begin{tabular}{|c|c|c|c|c|c|c|c|c|}
\hline \multirow[b]{3}{*}{ Field variable } & \multicolumn{8}{|c|}{ Field name } \\
\hline & \multicolumn{4}{|c|}{ 2009-10 season } & \multicolumn{4}{|c|}{ 2010-11 season } \\
\hline & GF1-1 & GF1-2 & GF1-3 & GF1-4 & GF2-1 & GF2-2 & GF2-3 & GF2-4 \\
\hline Field area $\left(\mathrm{m}^{2}\right)$ & 108 & 108 & 144 & 144 & 144 & 144 & 108 & 108 \\
\hline Number of subplots per field & 36 & 36 & 36 & 36 & 36 & 36 & 36 & 36 \\
\hline Subplot area $(\mathrm{m} \times \mathrm{m})$ & $1.5 \times 2$ & $1.5 \times 2$ & $2 \times 2$ & $2 \times 2$ & $2 \times 2$ & $2 \times 2$ & $1.5 \times 2$ & $1.5 \times 2$ \\
\hline Variety & Lintao157 & Lintao157 & Lintao 157 & Lintao157 & Lintao 157 & Lintao157 & Lintao157 & Lintao157 \\
\hline Seed-sowing date & 26-09-09 & 26-09-09 & 14-09-09 & $14-09-09$ & $28-09-09$ & 28-09-09 & $16-09-09$ & 16-09-09 \\
\hline Planting density (seeds $\left./ \mathrm{m}^{2}\right)$ & 450 & 450 & 450 & 450 & 450 & 450 & 450 & 450 \\
\hline Leaf sampling date & $19-03-10$ & $19-03-10$ & 19-03-10 & $19-03-10$ & $19-10-10$ & $19-10-10$ & $19-10-10$ & $19-10-10$ \\
\hline Fungicide treatment date & & & & & $27-10-10$ & & $27-10-10$ & \\
\hline \multirow[t]{3}{*}{ Disease assessment date } & $28-03-10$ & 28-03-10 & $28-03-10$ & $28-03-10$ & $11-11-10$ & $11-11-10$ & $11-11-10$ & $11-11-10$ \\
\hline & $\ldots$ & $\ldots$ & $\ldots$ & $\ldots$ & $21-11-10$ & $21-11-10$ & $21-11-10$ & $21-11-10$ \\
\hline & $\ldots$ & $\cdots$ & $\ldots$ & $\cdots$ & $01-12-10$ & $01-12-10$ & $01-12-10$ & $01-12-10$ \\
\hline
\end{tabular}

${ }^{a}$ Dates given in day-month-year format (e.g., 26-09-09 = 26 September 2009).

Table 2. Summary of experimental design in Shangzhuang, China, field plots during the 2009-10 and 2010-11 growing seasons ${ }^{\mathrm{a}}$

\begin{tabular}{|c|c|c|c|c|c|c|c|}
\hline \multirow[b]{3}{*}{ Field variable } & \multicolumn{7}{|c|}{ Field name } \\
\hline & \multicolumn{3}{|c|}{ 2009-10 season } & \multicolumn{4}{|c|}{ 2010-11 season } \\
\hline & SF1-1 & SF1-2 & SF1-3 & SF2-1 & SF2-2 & SF2-3 & SF2-4 \\
\hline Field area $\left(\mathrm{m}^{2}\right)$ & 36 & 36 & 36 & 36 & 36 & 36 & 36 \\
\hline Number of subplots per field & 36 & 36 & 36 & 36 & 36 & 36 & 36 \\
\hline Subplot area $(\mathrm{m} \times \mathrm{m})$ & $1 \times 1$ & $1 \times 1$ & $1 \times 1$ & $1 \times 1$ & $1 \times 1$ & $1 \times 1$ & $1 \times 1$ \\
\hline Variety & Jing0045 & Jing0045 & Jing0045 & Jing0045 & Jing0045 & Jing0045 & Jing0045 \\
\hline Seed-sowing date & 30-09-09 & 30-09-09 & 30-09-09 & $01-10-10$ & $01-10-10$ & $01-10-10$ & $01-10-10$ \\
\hline Planting density (seeds $/ \mathrm{m}^{2}$ ) & 420 & & 420 & 420 & 420 & 420 & 420 \\
\hline Leaf sampling date & $05-05-10$ & $05-05-10$ & $05-05-10$ & $08-05-11$ & 08-05-11 & $08-05-11$ & $08-05-11$ \\
\hline Fungicide treatment date & $\ldots$ & $\ldots$ & $\ldots$ & $10-05-11$ & $\ldots$ & $10-05-11$ & $\ldots$ \\
\hline \multirow[t]{3}{*}{ Disease assessment date } & $16-05-11$ & $16-05-11$ & $16-05-11$ & $14-05-11$ & $14-05-11$ & $14-05-11$ & $14-05-11$ \\
\hline & $\ldots$ & $\ldots$ & $\ldots$ & $19-05-11$ & $19-05-11$ & $19-05-11$ & $19-05-11$ \\
\hline & $\ldots$ & $\ldots$ & $\ldots$ & $24-05-11$ & $24-05-11$ & $24-05-11$ & $24-05-11$ \\
\hline
\end{tabular}

${ }^{a}$ Dates given in day-month-year format (e.g., 26-09-09 = 26 September 2009). 
(5'-CAGAAAGCGAGTGGAAAGATGAAAG-3')/TAG2473R (5' GCAAGGAGGACAAAGATGAGGAA-3') (14).

Real-time PCR amplifications were performed using the SYBR Green I fluorescent dye. Amplifications were conducted in a $20-\mu 1$ volume containing $10 \mu \mathrm{l}$ of SYBR Premix Ex Taq (TAKARA Corp., Dalian, China), $0.4 \mu$ l of ROX Reference Dye (50x), $1 \mu$ of template DNA, $1 \mu \mathrm{l}$ of either forward or reverse primer $(2 \mu \mathrm{M}$ each), and $7.6 \mu \mathrm{l}$ of distilled $\mathrm{H}_{2} \mathrm{O}$. The following conditions were used for real-time PCR with primer pair Pst-F/Pst-R: an initial preheat for $30 \mathrm{~s}$ at $95^{\circ} \mathrm{C}$, followed by 40 cycles of denaturation at $95^{\circ} \mathrm{C}$ for $5 \mathrm{~s}$, annealing at $65^{\circ} \mathrm{C}$ for $30 \mathrm{~s}$, and extension at $72^{\circ} \mathrm{C}$ for $30 \mathrm{~s}$. The following condition was used to amplify the fragment of wheat genomic DNA using the primer pair TAG2315F/TAG2473R: an initial preheat for $30 \mathrm{~s}$ at $95^{\circ} \mathrm{C}$, followed by 40 cycles of denaturation at $95^{\circ} \mathrm{C}$ for $5 \mathrm{~s}$, annealing at $67^{\circ} \mathrm{C}$ for $20 \mathrm{~s}$, and extension at $72^{\circ} \mathrm{C}$ for $30 \mathrm{~s}$. After each run, the corresponding melting curve was analyzed for each sample by determining the curve peak position to confirm the specific PCR product. By using the primer pair PstF/Pst-R and P. striiformis f. tritici DNA, the peak of melting curve was at 85.5 to $86^{\circ} \mathrm{C}$, with a range of 84 to $87^{\circ} \mathrm{C}$, whereas, using the primer pair TAG2315F/TAG2473 and wheat DNA, the peak of the melting curve was at 83.8 to $84.3^{\circ} \mathrm{C}$ with a range of 81.5 to $85^{\circ} \mathrm{C}$.

The standard curves with $10 \times$ serial dilutions were generated by using DNA standards for $P$. striiformis $\mathrm{f}$. tritici and wheat with known concentrations established by Pan et al. (14). Both standards for P. striiformis $\mathrm{f}$. tritici and wheat DNA were used in each run with the unknown samples. The equation for $P$. striiformis $\mathrm{f}$. tritici DNA using the primer pair Pst-F/Pst-R was $y=-0.2891 x+$ $9.1852\left(r^{2}=0.9946, P<0.001\right)$, where $x$ is the cycle threshold $(\mathrm{Ct})$ value and $y$ is the corresponding $\log _{10}$ DNA quantity in picograms. The equation for wheat DNA using the primer pair TAG2315F/ TAG2473 was $y=-0.48 x+16.11\left(r^{2}=0.9957, P<0.01\right)$, where $x$ is the $\mathrm{Ct}$ value and $y$ is the corresponding $\log _{10}$ DNA quantity in nanograms.

Data analysis. The previously defined MDX (14) was applied as MDX $=$ quantity of $P$. striiformis f. tritici DNA (picograms)/quantity of wheat DNA (nanograms) for each sample. The subplot data of both MDX and DX were analyzed by using the computer program SURFER (Surfer 8.0; Golden Software, Golden, CO) to show the spatial distribution of both MDX and DX for each field plot, from which the foci of MDX and DX could be identified. For each field plot in the first season, the replicated subplot data of MDX versus the corresponding DX were used in linear regression analysis with the GLM procedure of SAS (version 9.1; SAS Institute, Cary, NC).

Geostatistics were applied to determine the aggregation levels of both MDX and DX in the field plots. The variance-to-mean (VM) ratio (9) was measured to determine the aggregation level in the field plots as $V M=S^{2} / X$, where $S^{2}$ is the sample variance and $X$ is the sample mean. When $V M<1, V M=1$, and $V M>1$, the distributions were considered as a regular spatial pattern, a random pattern, and an aggregated pattern, respectively. The index of dispersion, $D$, as the ratio of the observed variance of the variable (MDX or DX) among the sampling units to the expected binomial variance (10), was also analyzed. The situations when $D>1, D=1$, and $D<1$ were considered as an aggregation pattern, a random pattern, and an under-dispersed pattern (20), respectively. Here, $(N-1) \times \mathrm{D}$ has a $\chi^{2}$ distribution under the null hypothesis of randomness with $N-$ 1 degrees of freedom (where $N$ is number of subplots in each field plot). Both $V M$ and $D$ were calculated for Gangu and Shangzhuang field plots for two seasons.

To evaluate the efficacy of the fungicide treatment on latent foci to reduce the disease, each field spatial distribution map of MDX or DX generated with SURFER was used to determine the latent

A 1

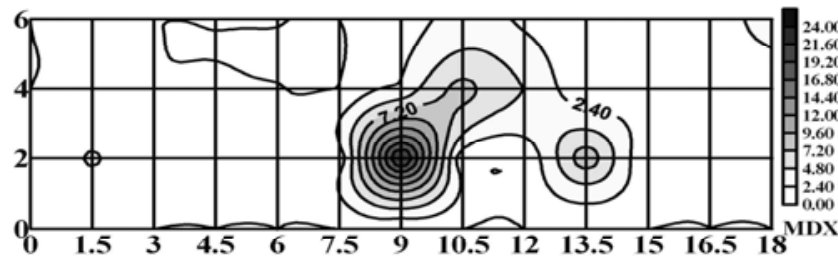

B 1

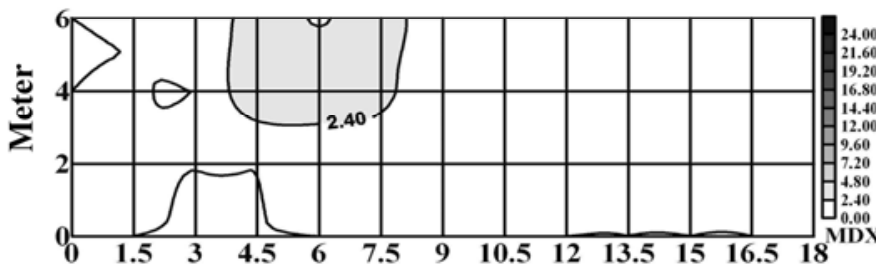

C 1

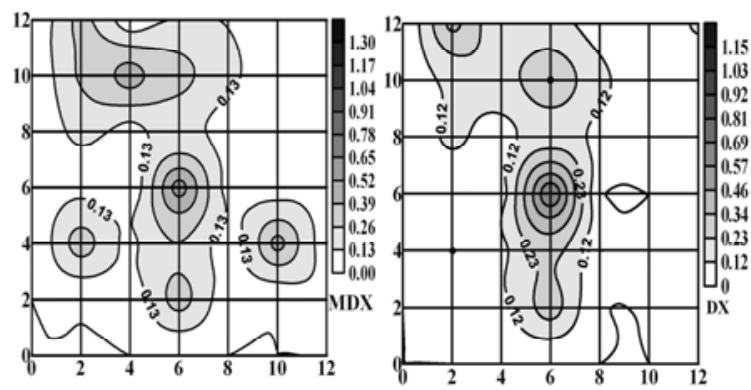

A 2

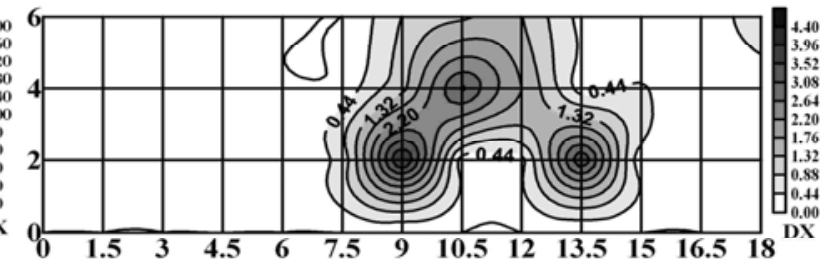

B 2

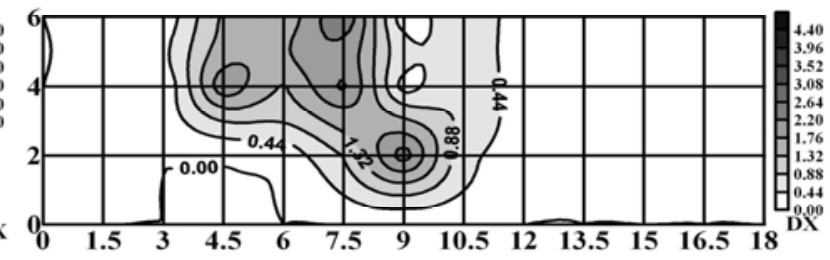

D 1

D 2
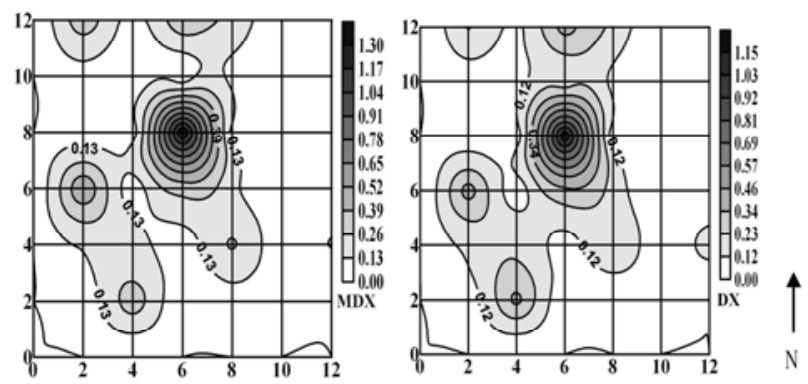

Meter

Fig. 1. Field distributions of molecular disease index (MDX) for wheat stripe rust in four field plots: A1, GF1-1; B1, GF1-2; C1, GF1-3; and D1, GF1-4. The corresponding stripe rust disease index (DX) for these field plots is shown in plates A2, B2, C2, and D2, respectively. Experiments were conducted in Gangu, Gansu Province of China during spring 2010. 
infection area and diseased area, respectively, by placing the corresponding distribution map on a small-grid-scale sheet (10 by 10 grids $/ \mathrm{m}^{2}$ ) to calculate the field latent infection area or disease area. In the nontreated control field plots, the disease area was usually greater than the latent infection area. Thus, the corrected proportion of disease area $(C)$ was calculated as $C=(\mathrm{Pd}-\mathrm{Pl}) / \mathrm{Pl}$, where $\mathrm{Pd}$ is the proportion of the disease area (disease area divided by the total area of the field as shown with DX), and $\mathrm{Pl}$ is the proportion of latent infection area (the area with detected latent infection divided by the total area of the field as shown with MDX). For each field, the average $C(\mathrm{CA})$ was calculated based on the data from the corresponding field plots. For the fungicide-treated fields, the corrected latent infection area (CLA) was calculated as CLA = LA $(1+\mathrm{CA})$, where LA was the latent infection area detected in a field plot.

The fungicide control efficacy was then estimated as $\mathrm{P}_{\mathrm{r}}=$ (CLA - DAT)/CLA $\times 100$, where $\mathrm{P}_{\mathrm{r}}$ is the percentage of reduction in disease area, and DAT is the disease area with fungicide treatment in the field. The average $\mathrm{P}_{\mathrm{r}}$ was calculated for the field plots having fungicide treatment. Additionally, for the 2010 autumn season in Gangu and 2011 spring season in Shangzhuang, the DX values versus the corresponding disease assessment dates were used to draw the disease progress curve, from which the area under the disease progress curve (AUDPC) was calculated for each field plot at the two locations using an SAS program generated by the authors.

\section{Results}

Gangu field plots. In GF1-1, a focus of latent infection at a higher level and two small foci with lower infection levels were identified (Fig. 1A1), which matched the DX distribution (Fig. 1A2). In GF1-2, latent infections were detected (Fig. 1B1), which developed to several disease foci around the area (Fig. 1B2). Moreover, when the smaller scale of MDX map was used in Figure 1B1, the distribution of latent infection matched that of DX (data not shown). The GF1-3 showed that five major latent infection foci were detected (Fig. 1C1) and three of them developed into major disease foci plus one with lower DX values (Fig. 1C2). Quite similar distributions between MDX (Fig. 1D1) and DX (Fig. 1D2) in GF1-4 were observed. The corresponding linear regressions between MDX and DX for these four field plots were all significant at $P=0.01$, with $r^{2}$ values of $0.8136,0.8845,0.5928$, and 0.9661 for GF1-1, GF1-2, GF1-3, and GF1-4, respectively.

In autumn 2010, GF2-2 showed a latent infection focus (Fig. 2B1) which developed to the disease focus at exactly the same location (Fig. 2B2). In GF2-1, three latent infection foci were identified (Fig. 2A1) and treated with the fungicide, which resulted in a clear distribution pattern for DX (Fig. 2A2). Similarly, a relatively severe latent infection focus was identified (Fig. 2D1), plus three foci with lower infection levels in GF2-4 (Fig. 2D1). Two of the latent infection foci developed to clear disease foci with low DX levels (Fig. 2D2), while the others did not (Fig. 2D2). Two major latent infection foci were identified in GF2-3 (Fig. 2C1) and treated with the fungicide, which resulted in a clear disease distribution (Fig. 2C2). Compared with the areas of the disease distribution in GF2-2 and GF2-4, the average $\mathrm{P}_{\mathrm{r}}$ in GF2-1 and GF2-3 was $72.9 \%$. The AUDPCs of GF2-1 and GF2-3 were 1.15 and 1.58 , respectively, while those of GF2-2 and GF2-4 were 5.18 and 10.53, respectively.

Shangzhuang field plots. In spring 2010, the field distribution patterns of MDX matched the field distribution patterns for disease in all three field plots (Fig. 3). The corresponding linear regressions between MDX and DX were all significant at $P=0.01$, with $r^{2}$ values of $0.7423,0.5784$, and 0.8584 for SF1-1, SF1-2, and SF13 , respectively.

In spring 2011, the detected latent infection foci (Fig. 4B1) all developed to the disease foci with various disease levels in SF2-2 (Fig. 4B2). For SF2-1, the identified latent infection foci were
A1

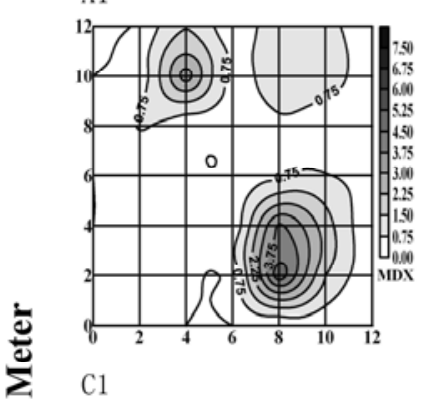

A2

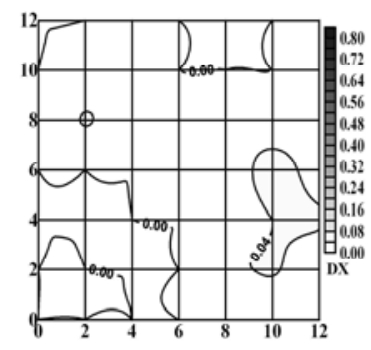

B1

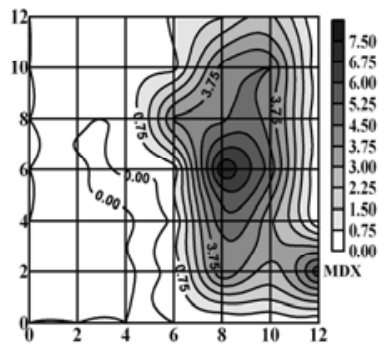

$\mathrm{C} 2$
B2

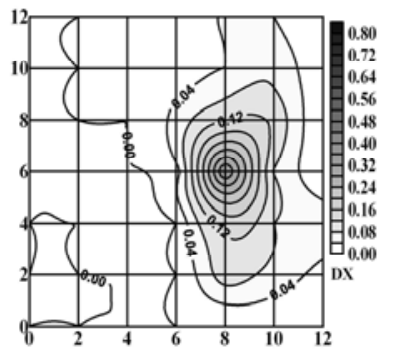

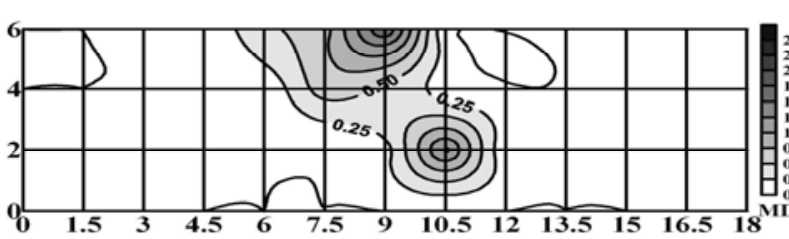

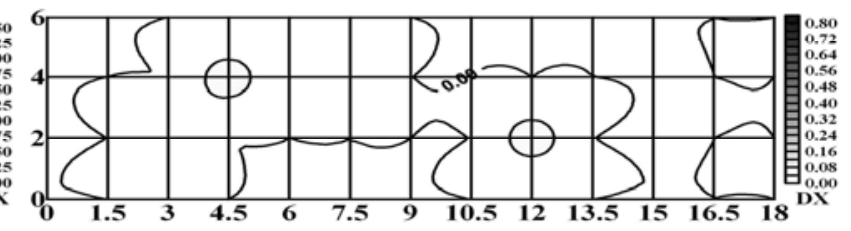

D2

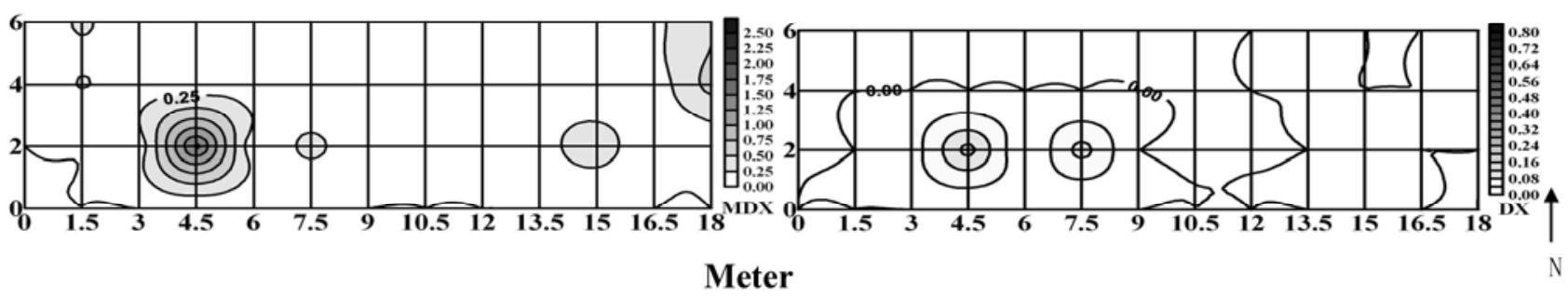

Fig. 2. Field distributions of the molecular disease index (MDX) for wheat stripe rust in four field plots: A1, GF2-1; B1, GF2-2; C1, GF2-3; and D1, GF2-4. The corresponding stripe rust disease index (DX) for these field plots is shown in plates A2, B2, C2, and D2, respectively. Experiments were conducted in Gangu, Gansu Province of China in autumn 2010. Field plots GF2-1 and GF2-3 were treated with the fungicide triadimefon $250 \mathrm{WP}$ at $374.8 \mathrm{~g} \mathrm{ha}^{-1}$ based on the latent infection foci detected in A1 and C1. Field plots GF2-2 (B1 and B2) and GF2-4 (D1 and D2) were nontreated plots. 
treated with the fungicide (Fig. 4A1), which resulted in a clear distribution pattern for DX (Fig. 4A2). Similarly, SF2-4 showed several latent infection foci (Fig. 4D1), which developed into disease foci (Fig. 4D2). In SF2-3, several latent infection foci were treated with the fungicide (Fig. 4C1), which resulted in a clear distribution pattern for DX (Fig. 4C2). Compared with the areas of the disease spatial distribution in SF2-2 and SF2-4, the average $P_{r}$ in SF2-1 and SF2-3 was 81.1\%. The AUDPCs of field plots SF2-1 and SF2-3 were 0.69 and 0.76 , respectively. Comparatively, the AUDPCs for field plots SF2-2 and SF2-4 were 2.49 and 2.62, respectively.

Geostatistical analysis (Table 3) demonstrated that the aggregation levels of MDX correlated well with those of DX, and the corresponding correlation coefficients for $V M$ and $D$ between
A 1

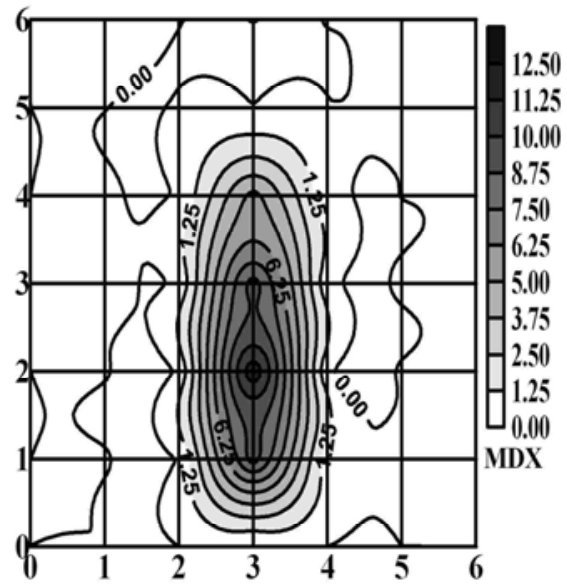

B 1

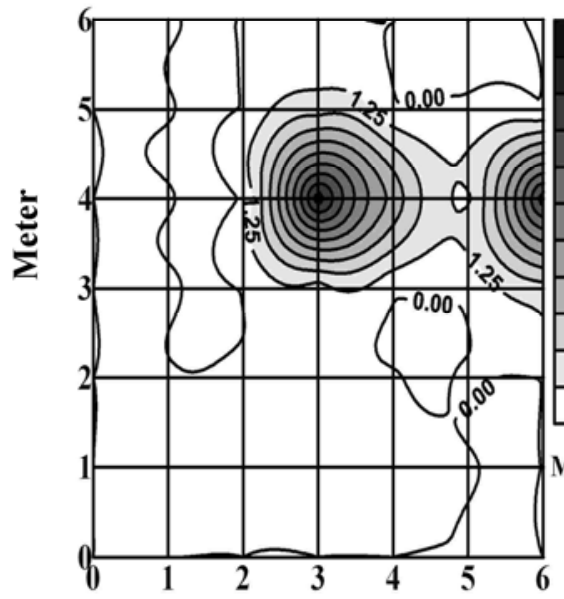

C 1

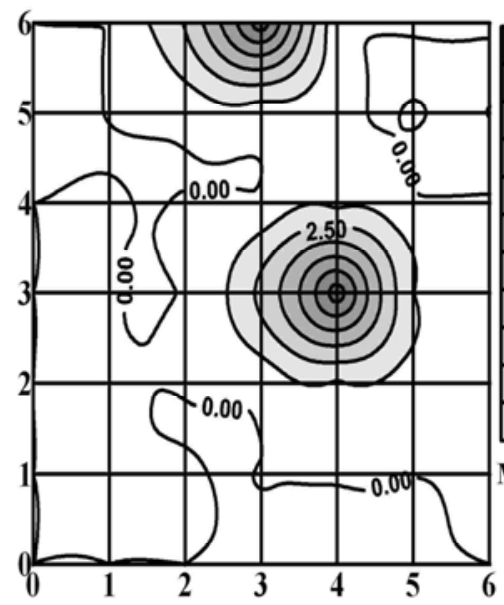

A 2

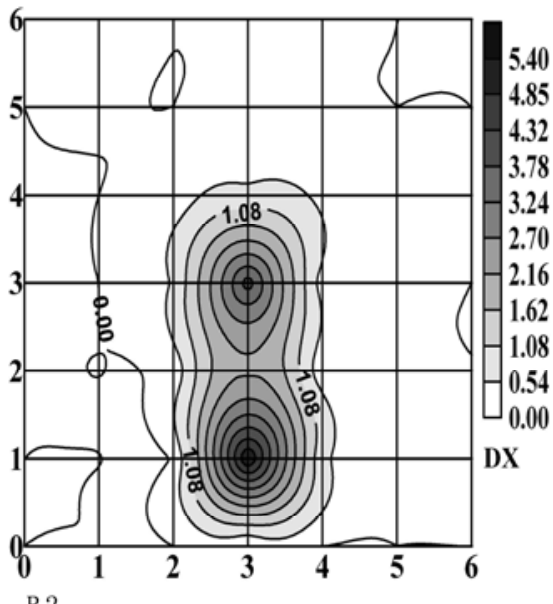

B 2

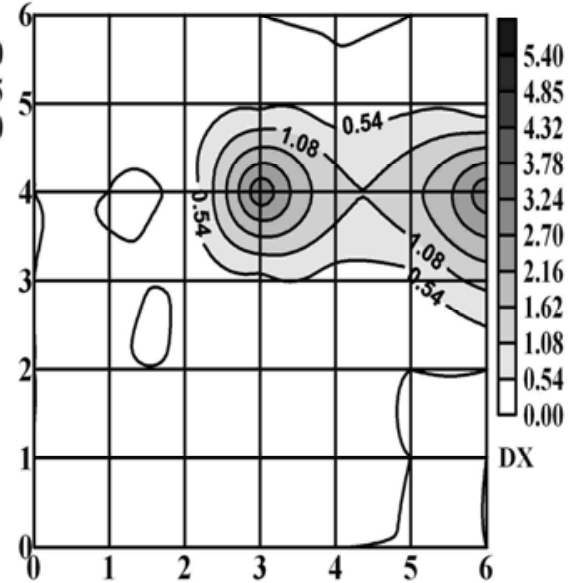

C 2

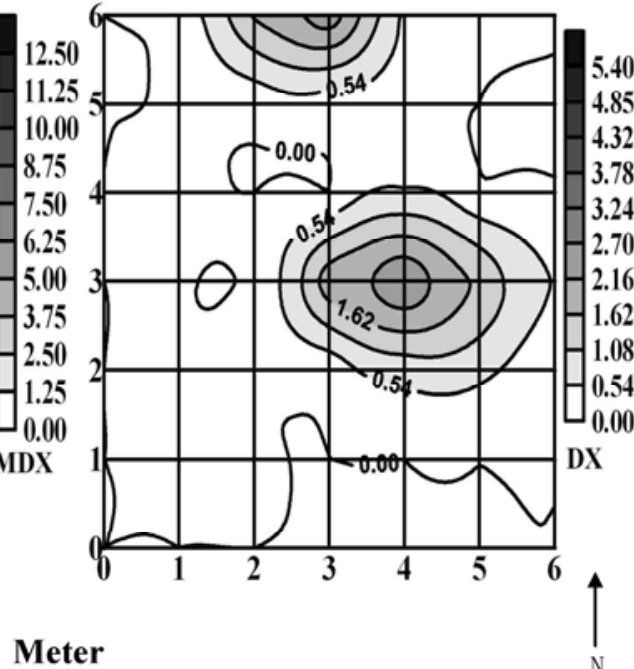

Fig. 3. Field distributions of the molecular disease index (MDX) for wheat stripe rust in three field plots: A1, SF1-1; B1, SF1-2; and C1, SF1-3. The corresponding stripe rust disease index (DX) for these field plots is shown in plates A2, B2, and C2, respectively. Experiments were conducted in Shangzhuang experimental center of China Agricultural University, Beijing, in spring 2010. 
MDX and DX were 0.88 and $0.91(P<0.01)$, respectively. The field plots of GF1-1, GF1-2, SF1-1, SF1-2, and SF1-3 showed high aggregation levels for both MDX and DX, while others exhibited under-dispersion (Table 3).

\section{Discussion}

The real-time PCR assay was shown to be a valuable approach for quantifying latent infection levels and estimating potential disease intensity for wheat stripe rust in the field. The field distribution of latent infection determined by the PCR assay matched the stripe rust field distributions. The average focus-targeting rates for Gangu and Shangzhuang were 71.4 and $85.7 \%$, respectively. By targeting latent infection foci with fungicide applications, the initial inoculum could be effectively reduced, lessening the chance for a rust epidemic.

MDX was used as a measurement of latent infection level which was quantified with real-time PCR. Measuring both $P$. striiformis $\mathrm{f}$. tritici and host DNAs, the MDX value takes into consideration not only the DI but also the DS. Good correlations between MDX and DX from this study demonstrated the usefulness of MDX to estimate potential disease intensity in the near future. However, disease development from latent infections in the field depends on many factors such as environmental (temperature, humidity, and solar radiation) and biological (host resistance and pathogen virulence) effects on disease development. In Gangu during spring 2011, latent infection levels were very low and very little disease developed. Thus, it seems impossible to obtain a standard and universal relationship between quantities of MDX and DX applicable to all fields. However, the approach can at least be used to determine whether latent infections exist in leaves. Because the major factor affecting appearance of stripe rust from latent infection is temperature (24), latent infection level can most likely be considered as the maximal potential of disease level in the near future. If this variable was combined with other approaches in which environmental and biological effects on disease are considered, the prediction of future disease intensity could be more accurate and applicable.

Improvement of the methodology used in this study to fit the needs for large-scale samplings and regional disease prediction will require additional work. To estimate initial inoculum intensities on a regional scale, appropriate sampling time, sampling method, and sample size need to be investigated further. The ultimate goal of this study was to establish an approach to quickly process large samples and accurately estimate possible inoculum intensity early in a season for large areas.

Using the information of detected MDX to estimate potential DX assumes that there is no exogenous inoculum. In other words, no new infections were assumed to occur during the prediction period. In the Shangzhuang field plots, the correlations in field distribution between MDX and DX were higher than those from the Gangu field plots. The weaker correlation at Gangu field plots may be due to exogenous inoculum. Thus, the variation or inaccuracy in estimation of $\mathrm{DX}$ by using MDX might become greater if new infections occur in the fields. The greatest potential for using this molecular approach is to estimate the latent infection levels just before and after winter in the locations where the epidemics get initiated.

The real-time PCR assay was effective at determining latent infection levels. The latent infection level can even be obtained on the same day as leaf sampling, making it possible to quickly obtain results. The unit cost per sample can also be reduced by processing larger samples. Thus, establishment of a standard system to routinely process field samples and to rapidly provide necessary information at the regional level might be possible.

The real-time PCR had been widely used to efficiently identify the plant pathogens (17) from samples of soil $(1,3,7)$, air $(8,19)$, seeds $(11)$, and plant tissues $(4,12,15,16,22)$ to quantify the inoculum or infection level. For instance, the real-time PCR assays were used to determine the correlations between DNA concentration of Fusarium graminearum in grain samples and the DI $(18,22)$, to quantify the rice leaf blast pathogen Magnaporthe grisea in rice leaf tissues and to screen for host resistance (15), to quantify the DNA of the pathogen Phaeocryptopus gaeumannii in needles of Douglas-fir early in the first year of colonization (23), to assess DS and quantify the development of fungal pathogens Alternaria brassicicola and Botrytis cinerea in Arabidopsis thaliana (4), and to quantify the infection level of Verticillium wilt diseases in olive root tissues caused by different Verticillium dahliae pathotypes (12). However, most studies did not focus on determining the spatial distribution of latent infection in the fields. This study provides an example in this area.
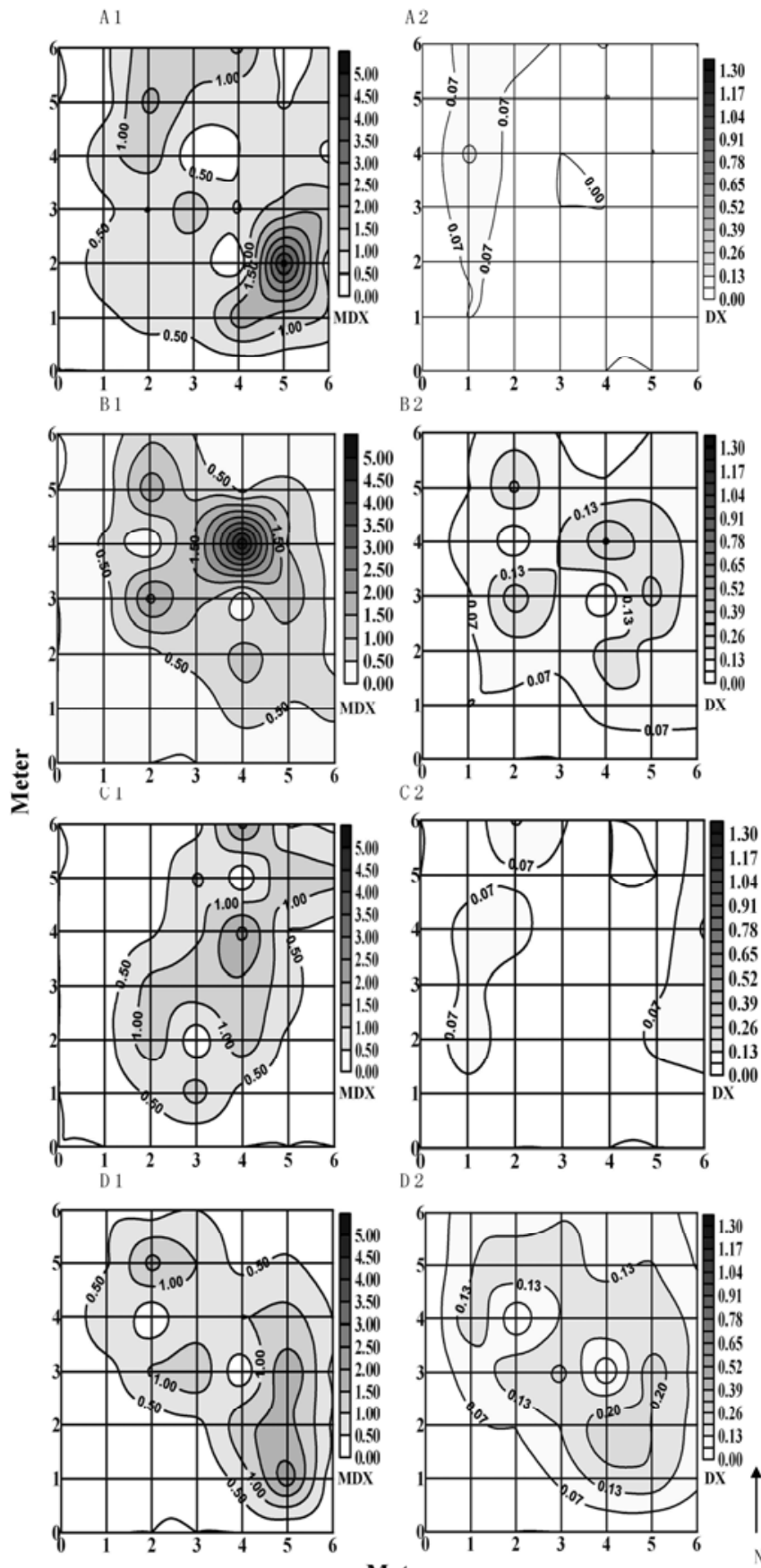

Meter

Fig. 4. Field spatial distributions of the molecular disease index (MDX) for wheat stripe rust in four field plots: A1, SF2-1; B1, SF2-2; C1, SF2-3; and D1, SF2-4. The corresponding stripe rust disease index (DX) for these field plots is shown in plates A2, B2, C2, and D2, respectively. Experiments were conducted in Shangzhuang experimental center of China Agricultural University, Beijing, in spring 2011. Field plots SF2-1 and SF2-3 were treated with the fungicide triadimefon 250WP at 374.8 $\mathrm{g} \mathrm{ha}^{-1}$ based on latent infection foci detected in A1 and C1. Field plots SF2-2 and SF2-4 served as nontreated controls. 
Table 3. Values of variance-to-mean $(V M)$, index of dispersion $(D)$, and the corresponding $\chi^{2}$ used to analyze aggregation levels of molecular disease index (MDX) and disease index (DX) of wheat stripe rust in different field plots of two locations in this study ${ }^{\mathrm{a}}$

\begin{tabular}{|c|c|c|c|c|c|c|c|}
\hline \multirow[b]{2}{*}{ Season } & \multirow[b]{2}{*}{ Field plot } & \multicolumn{3}{|c|}{ MDX } & \multicolumn{3}{|c|}{ DX } \\
\hline & & $V M$ & $D$ & $\chi^{2}$ & $V M$ & $D$ & $\chi^{2}$ \\
\hline 2009-10 & GF1-1 & 9.81 & 2.30 & 125.91 & 1.72 & 2.60 & 91.09 \\
\hline 2009-10 & GF1-2 & 1.84 & 0.55 & 23.37 & 1.00 & 1.51 & 53.00 \\
\hline 2009-10 & GF1-3 & 0.17 & 0.15 & 2.13 & 0.17 & 0.26 & 9.24 \\
\hline 2009-10 & GF1-4 & 0.38 & 0.11 & 4.82 & 0.29 & 0.44 & 15.57 \\
\hline $2010-11$ & GF2-1 & 1.63 & 0.49 & 20.79 & 0.03 & 0.04 & 1.52 \\
\hline 2010-11 & GF2-2 & 2.76 & 0.84 & 35.47 & 0.11 & 0.17 & 6.02 \\
\hline 2010-11 & GF2-3 & 0.79 & 0.24 & 10.01 & 0.05 & 0.07 & 2.72 \\
\hline 2010-11 & GF2-4 & 0.48 & 0.14 & 6.10 & 0.08 & 0.12 & 4.29 \\
\hline 2009-10 & SF1-1 & 7.78 & 2.36 & 99.20 & 2.92 & 4.40 & 154.06 \\
\hline 2009-10 & SF1-2 & 7.53 & 2.28 & 95.78 & 1.63 & 2.47 & 86.62 \\
\hline 2009-10 & SF1-3 & 4.92 & 1.48 & 62.57 & 1.32 & 1.98 & 69.33 \\
\hline 2010-11 & SF2-1 & 0.62 & 0.19 & 7.88 & 0.02 & 0.04 & 1.42 \\
\hline 2010-11 & SF2-2 & 1.16 & 0.35 & 14.82 & 0.04 & 0.05 & 2.06 \\
\hline 2010-11 & SF2-3 & 0.58 & 0.18 & 7.42 & 0.03 & 0.05 & 1.73 \\
\hline 2010-11 & SF2-4 & 0.57 & 0.17 & 7.19 & 0.04 & 0.06 & 2.11 \\
\hline
\end{tabular}

${ }^{\text {a }}$ MDX and DX were significantly correlated $(P<0.01)$ for $V M$ (correlation coefficient $=0.88$ ) and $D$ (correlation coefficient $=0.91$ ). MDX $=$ quantity of Puccinia striiformis f. tritici DNA (picograms)/quantity of wheat DNA (nanograms) for each sample. DX $=\mathrm{DI} \times \mathrm{DS} \times 100$, where DI $=$ disease incidence $=$ number of diseased leaves/total number of leaves assessed and DS = disease severity = average area with symptoms/average total leaf area. The $V M$ ratio was measured to determine the aggregation level in the field plots as $V M=S^{2} / X$, where $S^{2}$ is the sample variance and $X$ is the sample mean. $D$ was analyzed as the ratio of the observed variance of the variable (MDX or DX) among the sampling units to the expected binomial variance. Under the null hypothesis of randomness, $(N-1) \times D$ has a $\chi^{2}$ distribution, where $N$ is number of subplots in each field plot.

There is considerable potential for using this approach to aid in disease management in some regions of China (28), where the overwintering local inoculum plays an important role in spring epidemics. The initial inoculum potential can be determined just before the winter by determining the MDX values. Therefore, the growers may have enough time to prepare for disease management early the next spring or even treat the severe latent infection foci in the autumn. Early disease control can save time and costs through more timely disease management, especially at early low initial inoculum levels. For the regions where $P$. striiformis f. tritici can oversummer and infects seedlings in the autumn, early, efficient, and accurate determination of latent infection level plus timely disease management could significantly reduce the amount of potential inoculum. Although this study demonstrated the efficacy of disease management by fungicide application in latent infection foci early in the season, more intensive studies are needed which should involve multi-year, multi-location experiments under different disease intensity levels.

In terms of long-distance disease spread, significant reduction of inoculum in source regions could prove to be an important regional disease management strategy (28). Latent infection level has the potential to be combined with disease forecast models (29) to assess the possible risks of regional disease epidemics based on both disease levels and climatic and weather information.

\section{Acknowledgments}

This study was supported by the Special Fund for Agro-scientific Research in the Public Interest for project number 200903035. We thank G. Li and W. Kuang, China Agricultural University, for their assistance in DNA extraction of some samples; and X. Wang, Institute of Plant Protection, Gansu Academy of Agriculture Science, for efforts on assistance in field experiments.

\section{Literature Cited}

1. Cullen, D. W., Lees, A. K., Toth, I. K., and Duncan, J. M. 2001. Conventional PCR and real-time quantitative PCR detection of Helminthosporium solani in soil and on potato tubers. Eur. J. Plant Pathol. 107:387-398.

2. Enjalbert, J., Duan, X., Giraud, T., Vautrin, D., De Vallavieille-Pope, C., and Solignac, M. 2002. Isolation of twelve microsattelite loci, using an enrichment protocol, in the phytopathogenic fungus Puccinia striiformis f. sp. tritici. Mol. Ecol. Notes 2:563-565.

3. Filion, M., St.-Arnaud, M., and Jabaji-Hare, S. H. 2003. Direct quantification of fungal DNA from soil substrate using realtime PCR. J. Microbiol. Methods 53:67-76.

4. Gachon, C., and Saindrenan, P. 2004. Real-time PCR monitoring of fungal development in Arabidopsis thaliana infected by Alternaria brassicicola and Botrytis cinerea. Plant Physiol. Biochem. 42:367-371.

5. Li, Z. Q., and Zeng, S. M. 2002. Wheat Rusts in China. China Agricultural Press, Beijing.
6. Line, R. F. 2002. Stripe rust of wheat and barley in North America: a retrospective historical review. Annu. Rev. Phytopathol. 40:75-118.

7. Luo, Y., Gao, W., Doster, M., and Michailides, M. J. 2009. Quantification of conidial density of Aspergillus flavus and A. parasiticus in soil from almond orchards using real-time PCR. J. Appl. Microbiol. 106:1649-1660.

8. Luo, Y., Ma, Z., Reyes, H. C., Morgan, D. P., and Michailides, T. J. 2007. Quantification of airborne spores of Monilinia fructicola in stone fruit orchards of California using real-time PCR. Eur. J. Plant Pathol. 118:145-154.

9. Madden, L. V., and Hughes, G. 1995. Plant disease incidence: distributions, heterogeneity, and temporal analysis. Annu. Rev. Phytopathol. 33:529-564.

10. Madden, L. V., Hughes, G., and van den Bosch, F. 2007. The Study of Plant Disease Epidemics. American Phytopathology Society, St. Paul, MN.

11. McNeil, M., Roberts, A. M. I., Cockerell, V., and Mulholland, V. 2004. Real-time PCR assay for quantification of Tilletia caries contamination of UK wheat seed. Plant Pathol. 53:741-750.

12. Mercado-Blanco, J., Collado-Romero, M., Parrilla-Araujo, S., Dolores, Rodríguez-Jurado, D., and Jiménez-Díaz, R. M. 2003. Quantitative monitoring of colonization of olive genotypes by Verticillium dahliae pathotypes with real-time polymerase chain reaction. Physiol. Mol. Plant Pathol. 63:91105 .

13. O’Brien, L., Brown, J. S., Young, R. M., and Pascoe, I. 1980. Occurrence and distribution of wheat stripe rust in Victoria and susceptibility of commercial wheat cultivars. Aust. Plant Pathol. 9:14.

14. Pan, J.-J., Luo, Y., Huang, C., Sun, Z.-Y., Zhao, L., Yan, J.-H., and Ma, Z.H. 2010. Quantification of latent infections of wheat stripe rust by using real-time PCR. Acta Phytopathol. Sin. 40:504-510.

15. Qi, M., and Yang, Y. 2002. Quantification of Magnaporthe grisea during infection of rice plants using real-time polymerase chain reaction and northern blot/phosphoimaging analyses. Phytopathology 92:870-876.

16. Sandberg, M., Lundberg, L., and Ferm, M. 2003. Real-time PCR for the detection and discrimination of cereal contamination in gluten free foods. Eur. Food Res. Tech. 217:344-349.

17. Schena, L., Nigro, F., Ippolito, A., and Gallitelli, D. 2004. Real-time quantitative PCR: a new technology to detect and study phytopathogenic and antagonistic fungi. Eur. J. Plant Pathol. 110:893-908.

18. Schnerr. H., Niessen. L., and Vogel, R. F. 2001. Real time detection of the tri5 gene in Fusarium species by lightcycler-PCR using SYBR Green I for continuous fluorescence monitoring. Int. J. Food Microbiol. 71:53-61.

19. Schweigkofler, W., O'Donnell, K., and Garbelootto, M. 2004. Detection and quantification of airborne conidia of Fusarium circinatum, the causal agent of pine pitch canker, from two California sites by using a real-time PCR approach combined with a simple spore trapping method. Appl. Environ. Microbiol. 70:3512-3520.

20. Turechek, W. W., and Madden, L. V. 1999. Spatial pattern analysis of strawberry leaf blight in perennial production. Phytopathology 89:421-433.

21. Viljanen-Rollinson, S. L. H., and Cromey, M. G. 2002. Pathways of entry and spread of rust pathogens: implications for New Zealand's biosecurity N. Z. Plant Prot. 55:42-48.

22. Waalwijk, C., van der Heide, R., de Vries, I., van der Lee, T., Schoen, C., Costrel-de Corainville, G., Häuser-Hahn, I., Kastelein, P., Köhl, J., Lonnet, P., Demarquet, T., and Kema, G. H. J. 2004. Quantitative detection of Fusarium species in wheat using TaqMan. Eur. J. Plant Pathol. 110:481-494.

23. Winton, L. M., Stone, J. K., Watrud, L. S., and Hansen, E. M. 2002. 
Simultaneous one-tube quantification of host and pathogen DNA with realtime polymerase chain reaction. Phytopathology 92:112-116.

24. Xiao, Y. Y., and Zeng, S. M. 1985. Comparisons among three equations to predict apparent infection rates of wheat stripe rust. Sci. Sin. Ser. B2:151157.

25. Zadoks, J, C, 1961. Yellow rust on wheat, studies in epidemiology and physiologic specialization. Tijdschr. Plantenziekten 67:69-256.

26. Zadoks, J. C., Chang, T. T., and Konzak, C. F. 1974. A decimal code for the growth stages of cereals. Weed Res. 14:415-421.
27. Zadoks, J. C., and Schein, R. D. 1979. Epidemiology and Plant Disease Management. Oxford University Press, New York.

28. Zeng, S. M., and Luo, Y. 2006. Long-distance spread and interregional epidemics of wheat stripe rust in China. Plant Dis. 90:980-988.

29. Zeng, S. M., and Luo, Y. 2008. Systems analysis of wheat stripe rust epidemics in China. Eur. J. Plant Pathol. 121:425-438.

30. Zeng, X., Luo, Y., Zheng, Y., Duan, X., and Zhou, Y. 2010 Detection of latent infection of wheat leaves caused by Blumeria graminis f. sp. tritici using nested PCR. J. Phytopathol. 158:227-235. 